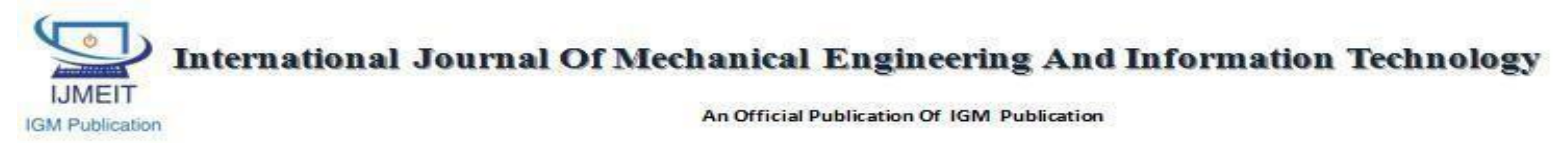

\title{
Evaluating the Safety Characteristics and Contributing Factors For Accident In Foundry Industry
}

\author{
DOI: http://dx.dloi.org/10.18535/ijmeit/v2i11.02 \\ Authors

\section{Nandakumar ${ }^{1}$, Arularasu $^{2}$} \\ ${ }^{1}$ Asst. Professor of Mech. Engg., Government College of Technology, Coimbatore, Tamilnadu, India \\ ${ }^{2}$ Principal, Thanthai Periyar Government Institute of Technology, Vellore, Tamilnadu, India \\ E-mail:nannthu@yahoo.com
}

\begin{abstract}
Occupational safety and health is a very imperative issue and is defined as the condition of being safe and to ensure that occupational accidents and work related ill health are prevented as much as possible, and safe working environment is promoted. The working environments in foundries are characterized by combination of mechanical, chemical, physical and environmental hazards to mankind. Safety performance is related to accident prevention. The measurement should enable one to compare the same accident producing characteristics of different objects, the accident producing characteristics of same objects at different times, and to describe how accident producing characteristics of the same or different things are related to each other. To examine this necessary ingredient of an accident as well as some of the characteristics of the ingredients involved in safety measurement are, worker, machine, tools or equipment, physical environment and social environment. Physical characteristics include anthropometrical dimensions, visual acuteness, and hearing perceptions. A comprehensive study is developed with human health risk assessment consisting of risk factors related with all of the possible risk sources in small scale foundry industry with hazardous materials and environmental aspects.
\end{abstract}

Keywords - Occupational safety, hazardous environment, situational model, safety characteristics

\section{INTRODUCTION}

Human resources constitute a vital role for the growth, development, productivity and all other aspects of the industry. Hazards originating from technological or industrial accidents, dangerous procedures, infrastructure failures or certain human wrong activities, which may cause the loss of life or injury, property damage, social and economic disruption or environmental degradation. Occupational Safety is an important aspect of Industries to protect the workers, supervisors, management and staff employed in them apart from improving productivity by reducing the losses that may arise due to occurrence of accidents. Asange, (1988), suggests that human reliability parameters are most varied, unpredictable and somewhat puzzling in nature, such that research in human behavior under various stresses and environmental conditions presents a wide field of investigation and tend to involve the realms of human psychology and physiology. Safety is concerned with reducing accidents and controlling or eliminating hazards at the work place environment.

Accident prevention is a significant step towards safety improvement. Sanders and McCormick (1993), says human factor researchers have, studied about variables as workers energy, strength, durability, speed, accuracy of movements, and workload. Knowledge gained from this research has promoted the strategy of work places that maximize human performance, and minimize such outcomes as fatigue, stress, and the errors to which they contribute. He argued that it is often easier to design a safe workplace rather than to make workers 
behave safely, but workers must learn to use their work equipment, and by, doing so are likely to make errors and have accidents. Nowadays there is consistent force exerted on companies to improve safety. Major factors for this force are economical, social and government regulations.

To provide a systematic and objective approach to assess hazards and their associated risks that will deliver an objective measure of an identified hazard as well as provide a method to control the risk. The two categories of model for safety causation are behavioral and situational model. In behaviour model the human factor is responsible for accident and in situation model, interaction between humans, environment and situation for studying the accident process.

\section{RISK ASSESSMENT TOOLS}

The workplace has attitude on health because of the multitude of hazards which exist in many working environments. Health effects can only occur if a worker is really exposed to the hazard. The risk of injury usually increases with the duration and frequency of person exposure to the agent, and the intensity or concentration and toxicity of the agent. Based on that the risk assessment is classified as Physical Methods: The physical method includes measurement of discomfort, study of workplace risks, observation of posture, measurement of work effort and tiredness, assessing biomechanical elements of the worker like lower back, upper and lower end

Physiological Methods: The various human factors under this are occupational stress related, heart beat rate and its variability, blood pressure, respiration rate, and eyelid movements, muscular skeleton activity and skin response are some of the parameters considered in this method.

Behavioural Methods: These methods are individual's psychological functions analysis, evaluation of job stress, acquisition and use of knowledge, workload analysis and prediction, and situational awareness for ergonomic risk assessment. Environmental Methods: This method concern with environmental parameters like, pollution, toxic gaseous, thermal conditions, indoor air quality, indoor illumination, noise and acoustic measures, vibration exposure.

Macro-ergonomics: This method focuses on organizational occupational behavioural methods, manufacturing work systems, anthropometric technology, assessment of work system intervention, and analysis of the structure and processes of work systems.

Predominantly, the casting industry forms the source of occupational safety and health problems, specific means and methods are needed to face this situation and tackle the consequences

\section{SAFETY PERFORMANCE CRITERION}

All risks should be assessed and have control significances assigned, based on the established level of risk.To access safety performance, two factors are considered for evaluation. First is need for safety criterion and second are its associated properties.

\subsection{Need for safety criterion.}

To improve safety performance and free from accident, control of accident is very essential. To test the effectiveness of control, measurement is significant. 'What to measure' is termed as criterion. Some of the tools for safety criterions are, Identifying problem zone

Forecast estimation

Carry out comparisons

Conducting trend analysis

Evaluation of safety improvement program

Assessment of Stress level of worker

\subsection{Associated properties}

The associated properties of the safety criterion are reliability and validity. If the reliability of the individual safety criterion is satisfactory, this means that workers can be rated in terms of accident vulnerability without considering their exposure and accident related characteristics. The valid criterion is satisfactorily suited to the object being measured. The measurement could enable one to compare the same accident producing characteristics of different objects, the accident producing objects at different time, how it is related to each other. 


\section{SAFETY CHARACTERISTICS}

Safety performance is related to accident prevention. The measurement should enable one to compare the same accident producing characteristics of different objects, the accident producing characteristics of same objects at different times, and to describe how accident producing characteristics of the same or different things are related to each other.

To examine this necessary ingredient of an accident as well as some of the characteristics of the ingredients involved in safety measurement are,

- worker,

- machine, tools or equipment

- physical environment

- social environment

' $\mathrm{A}_{\mathrm{L}}$ ' denotes the accident level indicating the degree of losses such as human injury, property, fatality, etc., then

$$
\mathrm{A}_{\mathrm{L}}=\int\left(\mathrm{W}_{\mathrm{ij}}\right),\left(\mathrm{O}_{\mathrm{tk}}\right),\left(\mathrm{P}_{\mathrm{el}}\right),\left(\mathrm{S}_{\mathrm{gm}}\right)
$$

$W_{i j}$ - is the combined effect of the $i^{\text {th }}$ worker's characteristics " $\mathrm{j}$ ” as related to safety. The worker characteristics are physical abilities and skill; it includes the anthropometric dimensions, visual acuity and hearing.

$\mathrm{O}_{\mathrm{tk}}$ - is the combined effect of $\mathrm{o}^{\text {th }}$ machine's characteristic " $\mathrm{k}$ " as related to safety. These characteristics include mechanical actions, location of machine controls and quality of maintenance,

$\mathrm{P}_{\mathrm{el}}$ - is the combined effect of physical environment "e" at location "l" as related to safety. These characteristics are temperature, humidity, illuminations, air conditioning and housekeeping method.

$\mathrm{S}_{\mathrm{gm}}$ - is the combined effect of the social environment of characteristics " $\mathrm{g}$ " at location ' $\mathrm{m}$ ' as related to safety. In this character, the regulations, rules and laws which influence the worker behavior are the social environment characteristics.

\section{CONTRIBUTING FACTORS FOR ACCIDENTS}

To completely recognize the grounds of an accident, a full understanding of the contributing and instantaneous causes of the accident is essential. Contributing factors of an accident, if corrected before the accidents happen are most likely to result in accelerating the accident prevention process. Three factors taken into account as the causes of accidents are

Supervisors Safety Performance

Mental condition of workers

Physical condition of workers

\subsection{Supervisor's safety performance.}

The safety performance of the supervisor may be evaluated by examining the following factors:

- Job hazard analysis

- Enforcement of safety rules

- Adequate safety knowledge

- Workers participation in safety

- Proper job placement

From hundred foundries surveyed, twenty foundries which have more than twenty workers were selected and standard questionnaires were given to the respective supervisor and workers in the foundry. Based on their feedback, points were allotted such as zero means poor, ten means satisfactory, twenty means good and twenty five excellent. The scoring of supervisors' safety performance is shown in table 5.1. According to the survey carried out in the sample companies the scoring performance of the supervisor is shown below.

\section{Table 5.1 Supervisors' safety performance} scoring

\begin{tabular}{|l|l|l|l|l|l|}
\hline \multicolumn{7}{|c|}{ Supervisors' safety performance } \\
\hline $\begin{array}{l}\text { Sample } \\
\text { Size }\end{array}$ & F1 & F2 & F3 & F4 & F5 \\
\hline S1 & 20 & 20 & 20 & 20 & 20 \\
\hline S2 & 25 & 25 & 25 & 20 & 25 \\
\hline S3 & 20 & 20 & 10 & 20 & 20 \\
\hline S4 & 0 & 3 & 10 & 0 & 0 \\
\hline S5 & 20 & 20 & 20 & 10 & 20 \\
\hline S6 & 0 & 10 & 0 & 0 & 10 \\
\hline S7 & 25 & 25 & 25 & 25 & 25 \\
\hline S8 & 20 & 20 & 20 & 20 & 10 \\
\hline S9 & 20 & 10 & 10 & 20 & 20 \\
\hline S10 & 0 & 0 & 0 & 0 & 0 \\
\hline S11 & 10 & 10 & 10 & 0 & 0 \\
\hline S12 & 25 & 25 & 25 & 25 & 25 \\
\hline S13 & 25 & 25 & 25 & 25 & 20 \\
\hline S14 & 0 & 0 & 0 & 10 & 0 \\
\hline S15 & 10 & 0 & 0 & 0 & 0 \\
\hline S16 & 20 & 10 & 10 & 10 & 10 \\
\hline S17 & 20 & 10 & 10 & 20 & 20 \\
\hline S18 & 10 & 0 & 0 & 0 & 10 \\
\hline S19 & 0 & 0 & 0 & 0 & 0 \\
\hline
\end{tabular}


The figure 5.1 shows the contributing conditions for accidents from the supervisor category. From the twenty sample companies, the validated performance scoring is shown below in which the supervisors from the companies 2,7,12 and 13 have received good scoring point such that the companies have a good working environment and very less chances of contributing factors towards accidents.

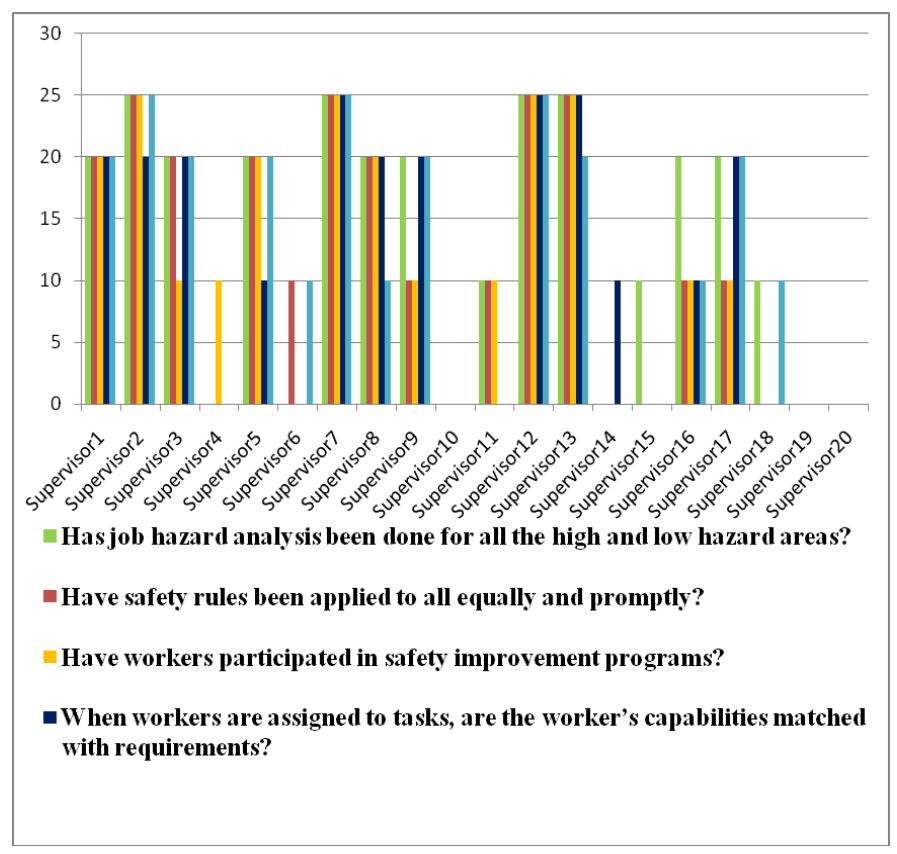

Figure 5.1 Supervisors' Contributing Condition for accidents

\subsection{Mental condition of workers}

The mental condition of the worker is an important factor with respect to occupational safety and health in the foundry environment. It is useful to consider the following factors.

- Safety awareness

- Eye hand co-ordination

- Worker's attitude

- Reaction and emotional stability

- Stress level of workers

From hundred foundries surveyed, twenty foundries which have more than twenty workers were selected and standard questionnaires were given to the respective workers in the foundry. Based on their feedback, score were allotted such as zero means poor, ten means satisfactory, twenty means good and twenty five excellent. In case of workers the value tabulated is the average value for the answers given by the five workers selected randomly. The average scoring of the mental condition of workers is shown in table 5.2

Table 5.2 Scoring for mental condition of workers

\begin{tabular}{|l|l|l|l|l|l|}
\hline \multicolumn{7}{|c|}{ Mental condition of workers } \\
\hline $\begin{array}{l}\text { Sample } \\
\text { Size }\end{array}$ & F1 & F2 & F3 & F4 & F5 \\
\hline W1 & 25 & 20 & 10 & 20 & 20 \\
\hline W2 & 25 & 25 & 25 & 25 & 25 \\
\hline W3 & 20 & 20 & 10 & 20 & 20 \\
\hline W4 & 10 & 10 & 0 & 0 & 0 \\
\hline W5 & 20 & 20 & 10 & 10 & 20 \\
\hline W6 & 0 & 10 & 0 & 0 & 10 \\
\hline W7 & 25 & 25 & 25 & 25 & 25 \\
\hline W8 & 20 & 20 & 10 & 20 & 10 \\
\hline W9 & 20 & 10 & 10 & 20 & 20 \\
\hline W10 & 0 & 10 & 0 & 0 & 0 \\
\hline W11 & 10 & 10 & 10 & 0 & 0 \\
\hline W12 & 25 & 25 & 25 & 25 & 25 \\
\hline W13 & 25 & 25 & 25 & 25 & 20 \\
\hline W14 & 0 & 10 & 0 & 0 & 0 \\
\hline W15 & 10 & 10 & 0 & 0 & 0 \\
\hline W16 & 25 & 20 & 10 & 10 & 10 \\
\hline W17 & 20 & 20 & 10 & 10 & 20 \\
\hline W18 & 10 & 10 & 10 & 0 & 10 \\
\hline W19 & 0 & 10 & 0 & 0 & 0 \\
\hline
\end{tabular}

The figure 5.2 shows the contributing conditions for accidents from the workers category based on their mental condition. From the twenty sample companies the validated performance scoring is shown below in which the workers from the companies have received adequate job trainings and exposure on safety related activities. These factors from the worker point of view shows the companies have a good working environment and very less chances of contributing towards accidents.

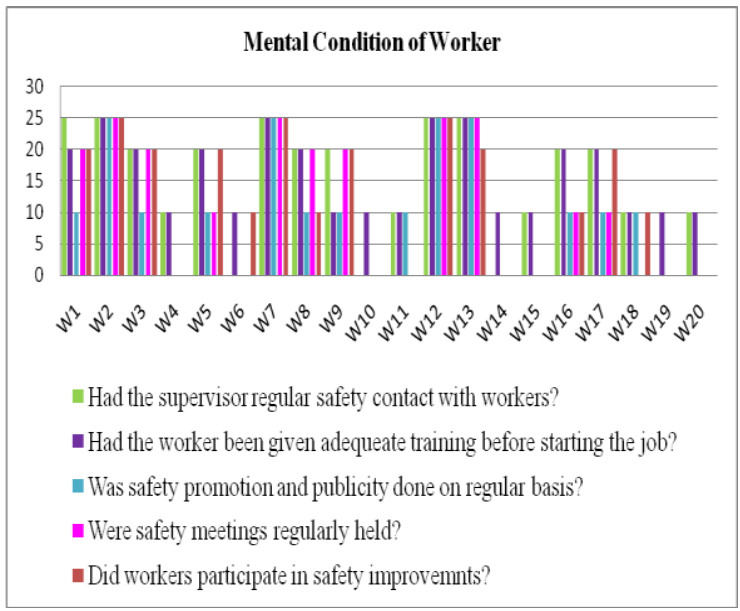

Figure 5.2 Workers contributing condition for accident 


\subsubsection{Physical condition of workers}

This is another important factor which calls for careful attention to the following, to find a worker with the required physical condition for performing the task, by medical examinations are necessary condition. Periodic re-examinations are needed to ensure that the environmental exposure is not affecting the workers physical condition adversely. In the event a worker is transferred from one job to another, a careful check of his/her physical conditions should be conducted.

From hundred foundries surveyed, twenty foundries which have more than twenty workers were selected and standard questionnaires were given to the respective supervisor and workers in the foundry. Based on their feedback, points were allotted such as zero means poor, ten means satisfactory, twenty means good and twenty five excellent. In case of workers the value tabulated is the average value for the answers given by the five workers selected randomly. The average scoring of the physical condition of workers is shown in table 5.3

Table 5.3 Scoring for Physical condition of workers

\begin{tabular}{|l|l|l|l|l|}
\hline \multicolumn{5}{|c|}{ Physical condition of worker } \\
\hline $\begin{array}{l}\text { Sample } \\
\text { Size }\end{array}$ & F1 & F2 & F3 & F4 \\
\hline W1 & 20 & 10 & 10 & 20 \\
\hline W2 & 25 & 25 & 25 & 25 \\
\hline W3 & 20 & 10 & 10 & 20 \\
\hline W4 & 10 & 10 & 0 & 0 \\
\hline W5 & 10 & 0 & 0 & 0 \\
\hline W6 & 0 & 10 & 0 & 0 \\
\hline W7 & 25 & 25 & 25 & 25 \\
\hline W8 & 20 & 10 & 10 & 10 \\
\hline W9 & 20 & 10 & 10 & 20 \\
\hline W10 & 0 & 10 & 0 & 0 \\
\hline W11 & 10 & 0 & 10 & 0 \\
\hline W12 & 25 & 25 & 25 & 25 \\
\hline W13 & 25 & 25 & 25 & 25 \\
\hline W14 & 0 & 10 & 0 & 0 \\
\hline W15 & 10 & 10 & 0 & 10 \\
\hline W16 & 20 & 10 & 10 & 20 \\
\hline W17 & 20 & 20 & 10 & 20 \\
\hline W18 & 10 & 10 & 10 & 0 \\
\hline W19 & 0 & 10 & 0 & 0 \\
\hline W20 & 10 & 10 & 10 & 0 \\
\hline
\end{tabular}

The figure 5.3 shows the contributing conditions for accidents from the worker category.

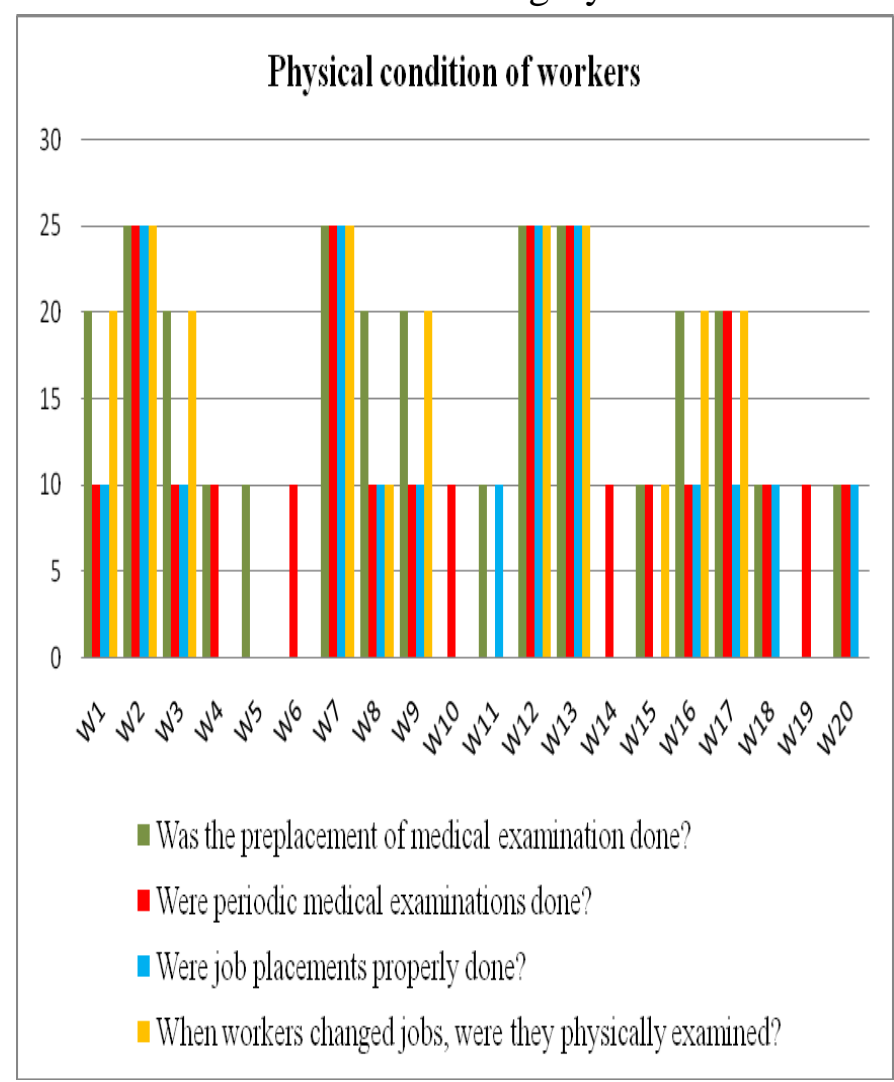

Figure 5.3 Physical ability of worker condition for accident

\section{ASSESSING CONTRIBUTING FACTORS}

Based on the obtained data the findings were tabulated for performance evaluation from the major contributing factors of accidents in the small scale industry. From the evaluation of contributing conditions for accidents, the findings shows that if the rating is between 1200 to 800, foundry has excellent working environment such that probability of accidents are very less. If the rating is between 500 to 800 , the foundry has satisfactory working environment such that less chances of accidents. If the Rating is less than 500, Foundry has poor working environment such that more chances of accidents takes place. 
Table 5.5 Evaluation of contributing factors

\begin{tabular}{|l|l|l|l|l|}
\hline Sample & $\begin{array}{l}\text { Supervisors } \\
\text { safety } \\
\text { performance }\end{array}$ & $\begin{array}{l}\text { Mental } \\
\text { condition } \\
\text { of workers }\end{array}$ & $\begin{array}{l}\text { Physical } \\
\text { condition } \\
\text { of workers }\end{array}$ & $\begin{array}{l}\text { Performance } \\
\text { evaluation } \\
(4 \mathrm{x}(1)+3 \mathrm{x}(2) \\
+3 \mathrm{x}(3))\end{array}$ \\
\hline F1 & 100 & 95 & 60 & 865 \\
\hline F2 & 120 & 125 & 100 & 1155 \\
\hline F3 & 90 & 90 & 60 & 810 \\
\hline F4 & 10 & 20 & 20 & 160 \\
\hline F5 & 90 & 80 & 10 & 630 \\
\hline F6 & 20 & 20 & 10 & 170 \\
\hline F7 & 125 & 125 & 100 & 1175 \\
\hline F8 & 90 & 80 & 50 & 750 \\
\hline F9 & 80 & 80 & 60 & 740 \\
\hline F10 & 0 & 10 & 10 & 60 \\
\hline F11 & 30 & 30 & 20 & 270 \\
\hline F12 & 125 & 125 & 100 & 1175 \\
\hline F13 & 120 & 120 & 100 & 1140 \\
\hline F14 & 10 & 10 & 10 & 100 \\
\hline F15 & 10 & 20 & 30 & 190 \\
\hline F16 & 60 & 70 & 60 & 630 \\
\hline F17 & 80 & 80 & 70 & 770 \\
\hline F18 & 20 & 40 & 30 & 290 \\
\hline F19 & 0 & 10 & 10 & 60 \\
\hline F20 & 0 & 20 & 30 & 150 \\
\hline
\end{tabular}

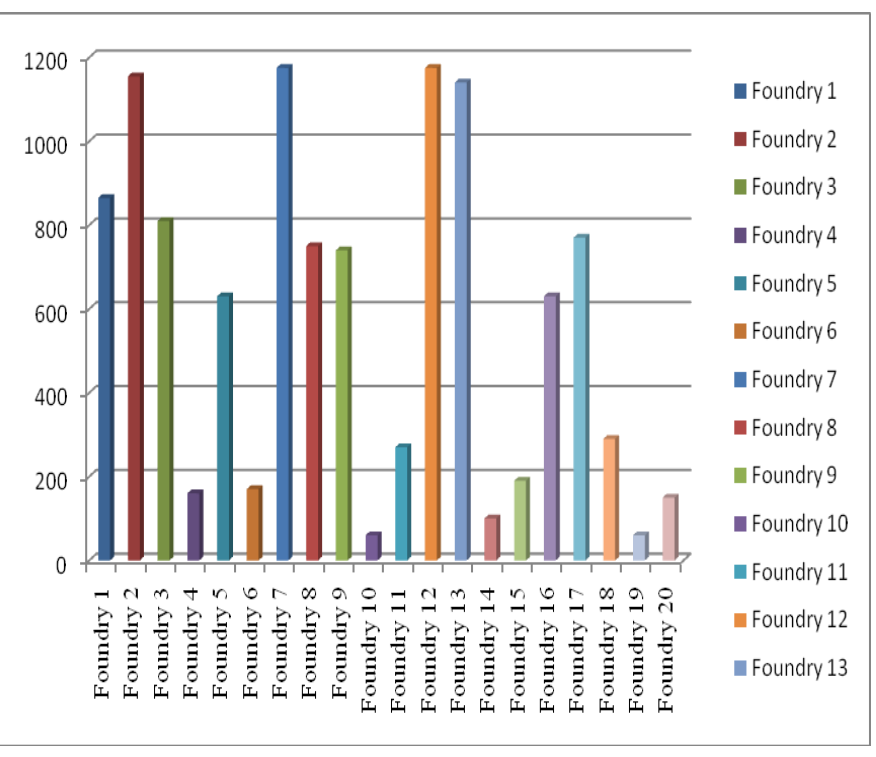

Figure 5.5 Overall performance ratings

The resulting graph shows the ratings obtained by the twenty foundries based on the contributing factors for accident. Only five foundries have good working environment and very less chances of contributing factors towards accidents. Six foundries have a satisfactory working environment for the workers and management and less chances of contributing factors towards accidents. Remaining nine foundries comes under poor working environment and had more chances of contributing factors towards accidents.

\section{CONCLUSION}

The study was carried out to investigate the quantitative safety assessment characteristics and the controlling factors and derive a clear-cut status on Occupational Safety and health hazard compliances in the small scale foundries such that the findings of the study will be utilized to protect workers by the reduction of accidents and dangerous occurrences. Considering the three contributing factors of accident and its related conditions, the overall performance rating shows that most of the foundries were under the occurrence of accidents. This clearly proves that these small scale foundries are not able to comply with legal requirements. It has been arrived through the research study that the small scale foundries do have Occupational, Safety and Environmental issues, which often result in accidents, injuries and ill health including fatal accidents.

\section{REFERENCES}

1. Guidelines for Hazard Identification, Risk assessment and Risk Control (HIRARC), Department of Occupational Safety and Health , Ministry of Human Resources, Malaysia, 2008. JKPP DP 127/789/4-47.

2. S. Zhang, C. Zhu, J. K. O. Sin, and P. K. T. Mok, "A novel ultrathin elevated channel low-temperature poly-Si TFT," journal name., vol. 20, pp. 569-571, Nov. 1999

3. Hansen, C. P. "Personality Characteristics of the Accident involved Employee", Journal of Business and Psychology, 1998 Vol. 2, pp.346-365.

4. Zhou Q, Fang D, Wang X. A method to identify strategies for the improvement of human safety behaviour by considering safety climate and personal experience. Saf Sci. 2008;46(10):1406-19 
5. Cox, S., Tomas, JM., Cheyne, A. \& Oliver, A.Safety culture: the prediction of commitment to safety in the manufacturing industry. British Journal of management. 1998, Vol.9, Special Issue, ppS3-S11

6. Toellner,J Improving safety and health performance: Identifying \& measuring leading indicators. Professional Safety, 2001, Vol.46, No.9, pp42-47

7. Dembe AE, Erickson JB, Delbos R. Predictors of work related injuries and illness: National Survey findings Occup Environ Hyg. 2004; 8:542-550.

8. Simard, M., \& Marchand, A. The behavior of first-line supervisors in accident prevention and effectiveness in occupational safety. Safety Science, 1994, 17, 169e185.

9. Flin, R., Mearns, K., O'Connor, P., \& Bryden, R. Measuring safety climate: identifying the common features. Safety Science, 2000, 34, 177e193.

10. Smith MJ, Cohen HH, Cohen A, Cleveland RJ. Characteristics of successful safety programs. J Safe Res 1978, 10:5-15

11.C.W.Cheng ,S.S.Leu ,C.C.Lin.,C. Fan.,CCharacteristic Analysis Of Occupational Accidents At Small Construction Enterprises. Safety Science, 2010 (480), 698-707

12. Bogner MS. The artichoke systems approach for identifying the why of error. In: Carayon $\mathrm{P}$, editor. Handbook of Human Factors in Health Care and Patient Safety. Mahwah, NJ: Lawrence Erlbaum; 2007. pp. 109-126 